(2) Open Access Full Text Article

ORIGINAL RESEARCH

\title{
Barriers of medication adherence in patients with type-2 diabetes: a pilot qualitative study
}

This article was published in the following Dove Press journal:

Diabetes, Metabolic Syndrome and Obesity: Targets and Therapy

\author{
Mehdi Rezaei ${ }^{1}$ \\ Sina Valiee ${ }^{2}$ \\ Mohammad Tahan ${ }^{3}$ \\ Fariba Ebtekar ${ }^{4}$ \\ Reza Ghanei Gheshlagh ${ }^{2}$ \\ 'Department of Social Sciences, Payame \\ Noor University (PNU), Tehran, Iran; \\ ${ }^{2}$ Clinical Care Research Center, \\ Kurdistan University of Medical Sciences, \\ Sanandaj, Iran; ${ }^{3}$ Young Researchers and \\ Elite Club, Birjand Branch, Islamic Azad \\ University, Birjand, Iran; ${ }^{4}$ Department of \\ Midwifery, School of Nursing and \\ Midwifery, Kurdistan University of \\ Medical Sciences, Sanandaj, Iran
}

Correspondence: Reza Ghanei Gheshlagh Clinical Care Research Center, Kurdistan University of Medical Sciences,

Pasdaran Ave, Sanandaj 6618634683, Iran Tel +98914 4050284

Email Ghanei@muk.ac.ir
Background: Patients with type-2 diabetes have poor adherence to the therapeutic regime. It can result in various complications in body systems associated with undesirable metabolic control.

Purpose: The present study aimed to explore the inhibitors of medication adherence in patients with type-2 diabetes.

Patients and methods: This was a qualitative study using a conventional content analysis method. Participants were 12 patients with type- 2 diabetes referred to the diabetes unit in Saghez, Kurdistan Province in 2015. The purposive sampling method was used with a maximum variation in sampling, and data collection was continued until data saturation was achieved. Semi-structured interviews were used for data collection. Interviews were recorded and immediately transcribed verbatim.

Results: Data analysis led to the development of four main categories including disbelief in medical explanatory/prescriptive knowledge, lived experiences of the disease, challenges of everyday life, and interactive/economic challenges. The main inhibitors were the patient's understanding of his/her own physical status and strategies used for maintaining the internal balance. Healthcare providers need to take patients' perceptions into account when they are prescribing medicinal diets. Another inhibitor was the incidents of everyday life, including economic and social challenges, and interactions to receive education and skills for living with the disease.

Conclusion: Beliefs of the medical team and patients should be brought closer to each other, and patients' trust in the medical team should be increased. Nurses should consider the unique experience of every patient when giving healthcare recommendations, and try to limit the existing challenges as much as possible.

Keywords: medication adherence, diabetes mellitus, content analysis

\section{Introduction}

Diabetes is a silent epidemy that affects $3.8 \%$ of the world's population. ${ }^{1}$ More than 4 million people in Iran suffer from diabetes, and it is expected to reach 6 million due to population aging, increasing prevalence of obesity, and lifestyle and dietary changes. ${ }^{2,3}$

Diabetes mellitus affects all aspects of the person's life. ${ }^{4}$ Management of diabetes requires a complex treatment regimen and lifestyle changes to improve adhere to treatment. ${ }^{5,6}$ Behavioral changes are the basis of treatment for chronic diseases, and failure to adhere to treatment is a common problem in patients with type- 2 diabetes. ${ }^{7}$ Similar to patients other with chronic conditions, patients with diabetes have poor adherence to treatment. For instance, out of 17 chronic diseases, diabetes is in the 
second rank in terms of low adherence to treatment. Therefore, diabetes is the second leading cause of hospitalization due to non-adherence to treatment. ${ }^{8,9}$

Adherence behaviors in patients with type- 2 diabetes include five categories: adherence to medication, dietary recommendations, increased physical activity, self-control of blood glucose, and proper care of legs. ${ }^{8}$ Failure to adhere to the therapeutic regimen accelerates the complications of diabetes. ${ }^{10}$ In a study by Osborn et al, the prevalence of adherence to oral glucose-lowering drugs was $36-87 \%$, and prevalence rates ranging from $54 \%$ to $81 \%$ were reported for adherence to insulin alone or insulin and glucose-lowering drugs. ${ }^{11}$ In a study by Delamater et al, adherence to physical activity and diet was found to be $19 \%$ and $65 \%$, respectively, and only $5 \%$ of the patients taking glucose-lowering oral pills monitored their blood sugar in a daily manner. ${ }^{12}$ A review study by Mashrouteh et al showed that the prevalence of treatment adherence in Iranian patients with diabetes varied from $37.2 \%$ to $87 \%{ }^{13}$ In addition, Ho and Boye found prevalence rates of $21.3 \%$ and $36.9 \%$ for treatment adherence, respectively. ${ }^{14,15}$

In a qualitative study among patients with diabetes in Qatar, Jaam et al found three categories of factors, including patient-related factors, patient-provider factors, and societal and environmental factors as barriers to treatment adherence. ${ }^{16}$ In another study, poor medical team performance, social dilemma, and personal distress were identified as factors preventing treatment adherence among diabetic patients. ${ }^{17}$

Given that in quantitative studies only pre-determined dimensions of a phenomenon are specified, qualitative studies can be useful in assessing concepts like treatment adherence that may be influenced by many unknown, context-dependent factors. In qualitative studies, a relatively more comprehensive discovery of the phenomenon of interest is performed. Qualitative studies are also useful for the completion and restoration of knowledge gained using quantitative approaches, through exploration of experiences and perspectives of individual participants. In other words, the phenomenon of interest is studied from the perspectives and experiences of the people involved.

The individuals' interpretations take priority, and efforts are made to link them to the social context. It means that the disease is analyzed through the person's way of life, experience of the world, and interaction with other people. ${ }^{18}$ The present study was conducted using a qualitative approach to explain adherence to treatment in patients with diabetes in Saghez, Kurdistan province, Iran. Like all other societies, the community under the study has its own culture, including a particular nutritional style (high consumption of bread, sugar, fat, and rice), lack of appropriate exercise for maintaining or improving health, gender norms putting women in a lower status than men, presence of economic issues, and a high unemployment rate.

Considering the important role of nurses in providing care for these patients and the relationship they have with them, identification of barriers to treatment adherence can be useful in prevention and control of the complications of diabetes, and can ultimately reduce hospital admissions, treatment costs, and mortality rates among patients. The researcher who had worked in clinical settings and observed non-adherence to treatment among patients, sought to investigate the causes of it from the perspectives of the patients themselves. She also sought to understand the rationale for nonadherence to treatment and the related individual and social conditions influencing adherence/ non-adherence to treatment. So, she had the following questions in mind:

1. Why patients with type-2 diabetes do not adhere to their therapeutic regimen?

2. How do they interpret this non-adherence?

\section{Methodology}

This was a qualitative study with the purpose of explaining low adherence to treatment in patients with type-2 diabetes. Participants were selected from patients with type-2 diabetes with medical records in the diabetes center of Saghez, Kurdistan province, Iran. Participants were selected using a purposeful sampling method until reaching data saturation. The research environment was the diabetes center of Saghez as the second most populous city in Kurdistan province, inhabited by Kurds practicing Sunni Islam. Twelve participants ( 7 women and 5 men) aged between 30 and 78 years were recruited. Four patients used insulin to control their disease and the rest used glucose lowering pills. After coordinating with the participants, interviews were conducted at the diabetes center in a quiet room. The demographic description of the participants is shown in Table 1.

After obtaining permissions from the health and treatment center authorities, the study objectives and processes were described to the participants. Their consent for participation in the study and their permission to tape-record the interviews were obtained. In this study, the main method of data collection was in-depth and semi- 
Table I Demographic description of the participants

\begin{tabular}{|l|l|l|l|l|l|}
\hline Code & Age & Gender & Duration of the disease & Education & Type of Medicine \\
\hline PI & 78 & Female & 24 & Illiterate & Insulin \\
P2 & 48 & Male & 8 & Illiterate & Oral medicine \\
P3 & 55 & Female & 14 & Illiterate & Insulin \\
P4 & 50 & Female & 10 & Illiterate & Oral medicine \\
P5 & 52 & Female & 12 & Primary & Oral medicine \\
P6 & 55 & Male & 7 & Illiterate & Oral medicine \\
P7 & 48 & Female & 11 & Primary & Oral medicine \\
P8 & 58 & Male & 20 & Intermediate & Insulin \\
P9 & 60 & Male & 18 & Academic & Insulin \\
PI0 & 45 & Female & 9 & Illiterate & Oral medicine \\
PII & 43 & Female & 8 & Intermediate & Oral medicine \\
P12 & 35 & Male & 3 & Intermediate & Oral medicine \\
\hline
\end{tabular}

structured interviews, because it is related to a higher flexibility and more depth of data collection. ${ }^{19}$ The interviews were conducted by the corresponding author who had received adequate training on conducting qualitative interviews and studies during his $\mathrm{PhD}$ studies. Before beginning the interviews, several pilot interviews were conducted, and the interview guideline was reviewed and modified by the research team. This study was conducted in accordance with the Declaration of Helsinki and written informed consent was provided by the participants. The interviews began with a general and open question, "How did you find out that you had diabetes?" The participants were asked about the medical centers they had been referred to for controlling their illness, the recommendations they had received, the problems they had encountered in following the recommendations, and the factors making them unable to follow treatment recommendations. The interviews lasted between 20 and 40 mins, with an average of 30 mins (Supplementary material). The interviews were performed individually in the counseling room of the diabetes center. All the interviews were recorded and immediately transcribed verbatim. The present study had a qualitative design. Qualitative studies explain people's experiences in everyday life. In a qualitative study, the researcher does not influence the study environment, and only tries to recognize and understand participants' everyday lives as they are. ${ }^{20}$ A conventional content analysis method was used to analyze the data. This method is used to interpret the content of textual data. ${ }^{21}$ Data analysis was performed alongside the interviews, based on the method suggested by Lundman and Graneheim: 1) transcription of the entire interviews as quickly as possible; 2) reading the entire interview transcript to get an overall understanding of the content; 3 ) determination of manifest units and primary codes; 4) classification of similar codes to more comprehensive categories; and 5) determining the latent content. ${ }^{22}$ For immersion in the data, the researcher listened to the interviews several times, and reviewed the transcriptions and the related recordings. Interview transcriptions were read line by line, words and phrases related to the study objective were identified, and original codes were extracted. All the codes were discussed with the other members of the research team, and if they were confirmed, the next stage of coding would be conducted. Subsequently, similar codes were conceptually conceptualized and classified into categories. Next, the corresponding categories led to the development of latent contents and concepts.

The Lincoln and Guba's criteria (credibility, dependability, conformability and transferability) were used for rigour. Credibility was achieved through maximum variation in participants, age, disease duration, financial status, and social status. To eliminate any ambiguity during the coding process, the interview transcripts and the related coding were presented to the participants to find similarities between the participants' and researchers' perspectives, and improve convergence between the study findings and the lived experiences of the participants. Dependability was achieved through collecting data regularly, recording and writing the steps and trends of the study, and checking the stability of findings by colleagues who were familiar with qualitative studies.

Ethical considerations included obtaining permission from authorities to enter the healthcare network, obtaining 
the informed consent of the participants, use of nicknames instead of actual names to ensure anonymity, keeping the confidentiality of the data, and possibility of withdrawal at any time without being penalized.

\section{Results}

The participants included 12 people with type- 2 diabetes ( 7 women and 5 men). The mean age of the participants and the mean duration of diabetes was 52 years and 12 years, respectively. The codes extracted from the interviews were divided into 8 subcategories and 4 main categories. According to the results, the barriers to treatment adherence among diabetic patients were as follows: Lack of trust in medical explanatory/prescriptive knowledge, lived experiences of the disease, challenges of everyday life, and interactive/economic challenges (Table 2).

\section{Lack of trust in medical explanatory/ prescriptive knowledge}

It was found that the patients with diabetes did not have a deep understanding of the medical knowledge on diabetes in many aspects, and had little faith in doctors' prescriptions and recommendations. They took medications based on their judgment of their physical condition. According to their comments, they did not believe in the doctors' advice and medical science. They considered doctor's recommendations nothing than "words", which rooted in a "lack of knowledge" of scientific facts about diabetes. They were unaware of the true causes of diabetes and instead believed in superstition or had misconceptions about their illness. They accepted recommendations or interpretations from their family members or other patients with diabetes rather than physicians. For example, one of the participants said: "Some people say: 'Don't inject insulin as you'll get used

Table 2 Categories and subcategories developed during the data analysis

\begin{tabular}{|c|c|c|}
\hline Main category & Subcategory & Primary category \\
\hline $\begin{array}{l}\text { Lack of trust in medical explanatory/pre- } \\
\text { scriptive knowledge }\end{array}$ & $\begin{array}{l}\text { Folk beliefs } \\
\text { Non-adherence to therapeutic } \\
\text { regimen }\end{array}$ & $\begin{array}{l}\text { - Misconceptions about diabetes } \\
\text { - False beliefs } \\
\text { - Ignorance } \\
\text { - Self-medication } \\
\text { - Voluntary disorganization of drug use consumption } \\
\text { based on self-perception }\end{array}$ \\
\hline Knowledge, lived experiences of the disease & $\begin{array}{l}\text { Medication side effects; } \\
\text { Physical challenges }\end{array}$ & $\begin{array}{l}\text { - Mouth bitterness } \\
\text { - Blurred vision } \\
\text { - Tremor } \\
\text { - Itching } \\
\text { - Knee pain } \\
\text { - Arthritis } \\
\text { - Dyspnea } \\
\text { - Obesity }\end{array}$ \\
\hline Challenges of everyday life & $\begin{array}{l}\text { Mental/psychological stress; } \\
\text { Preoccupations of the everyday life }\end{array}$ & $\begin{array}{l}\text { - Sadness } \\
\text { - Discomfort } \\
\text { - Disappointment } \\
\text { - Fear of the future } \\
\text { - Nervousness } \\
\text { - Heavy homework } \\
\text { - Housekeeping affairs } \\
\text { - Daily activities }\end{array}$ \\
\hline Interactive/economic challenges & $\begin{array}{l}\text { Lack of empathy/behavioral affiliation; } \\
\text { Weakness/financial dependence }\end{array}$ & $\begin{array}{l}\text { - Being ignored by family members } \\
\text { - Lack of support from family } \\
\text { - Marital conflicts } \\
\text { - Lack of skills } \\
\text { - Financial strain } \\
\text { - Impoverishment } \\
\text { - Financial dependence }\end{array}$ \\
\hline
\end{tabular}


to it'. I didn't follow their recommendation to receive insulin" (Participant 1).

Patients with diabetes also did not adhere to their medications, because of the above-mentioned beliefs, having misunderstandings or misperceptions about medical prescriptions, or lack of knowledge about how to use their medication. Taking medication was dependent on their condition rather than doctor's order. One participant, a 50 yearold woman, said: "Every time my blood glucose goes up, I sweat a lot, then I know that my blood sugar is high, and I take two or three pills." (Participant 4). Therefore, while neglecting the medical instructions, the patient deliberately uses this neglect to fulfill their own desires. It means that after overusing sugary foods (due to excessive appetite or inability to refrain from delicious foods), they prescribe a certain dose of medicine for themselves to prevent the harmful effects. A 60 year-old male diagnosed with type- 2 diabetes more than 7 years ago, said:

"I inject insulin to eat sweets and candy as much as I want. I know that I'll have troubles after eating sugary foods. That's why I raise my medication doses. I know myself well." (Participant 6).

\section{Lived experiences of the disease}

It means that the patient with diabetes experiences physical or mental problems, which are the results of the treatment of diabetes. On the other hand, these experiences may result from specific physical conditions that are separate from diabetes and result for other chronic conditions, such as arthritis, hyperlipidemia, shortness of breath, hypertension, and so on. An individual with diabetes has to take several pills and inject insulin to control their blood glucose levels. Patients with diabetes have to cope with unpleasant physical conditions that may not have been present before. This inconvenience is not permanent, however it is unbearable for some patients, and interferes with their normal life. Therefore, the patient violates the prescribing process. These experiences greatly affect the quality of life of patients, and increase the likelihood of medication discontinuation. From the perspective of patients, the medication side effects are more problematic than the treatment itself. A participant said: "Sometimes I take a pill, it's nauseous, I get sad, my body gets itching so bad that I want to pill if off, " (Participant 12). Therefore, the patient experiences a behavioral and functional conflict. Non-adherence to prescription causes changes in the blood glucose levels, and may lead to irreversible physical impairments. On the other hand, medications may have side effects interfering with the patient's daily life. In this regard, the person with diabetes must choose between taking and not taking medications. Occasionally, by changing the type or dosage of medications, diabetic patients try to manage the side effects.

"I change the dose of medications to reduce the severity of
discomfort. For example, if I need to take two pills a day, I
reduce it to one to experience less discomfort. Nausea
makes my life bitter". (Participant 5).

Given that the majority of patients with diabetes are older adults, they also experience other chronic conditions. The experience of these conditions undoubtedly increases the burden of the disease on the patient, and inevitably leads to more pain and suffering, exacerbates the effects of diabetes, and prevents the effectiveness of the treatment.

"I have hypertension and diabetes, my shoulders ache, and I have asthma. Due to these problems, I shouldn't walk very much, but I can go everywhere. The doctor said that I shouldn't walk, because it could make my arthritis worse. She said "walking was prohibited for me" (Participant 2).

Hypertension, diabetes, and dyspnea have concurrent effects that interfere with the treatment of each condition. Therefore, the patient with diabetes experiences a very specific condition that actually challenges health management. It is sometimes necessary to give up the management of one condition in favor of treating other conditions.

"I can't walk a lot, because of the shortness of breath. That is why I'm always worried about my hypertension. Diabetes is worse than ever. I say to myself that it's okay and the pills can control my blood pressure, it's not that bad, sometimes I don't take my blood glucose pills ... It's better than experiencing shortness of breath in the street. Honestly, I don't know which condition I should take care of". (Participant 2)

An important issue is self-management, which is also important from the patients' perspectives.

"Sometimes I try to avoid blood sugar spikes by avoiding eating. That's why I use less pills." (Participant 7).

\section{Challenges of everyday life}

Similar to other people in the community, those with type2 diabetes are involved in the everyday life. Occupation, interaction with children, marital duties, caring for a disabled spouse, neuropsychological and emotional 
disturbances caused by life events, work environment etc. all can affect the lives of diabetic patients. If patients experience stressful conditions, their treatment is undoubtedly influenced.

"Sometimes I'm so worried about providing for my family that I forget to check my blood sugar and take my medications. Sometimes experiencing a psychical problem has reminded me that I should take my drugs." (Participant 7)

One of the participants diagnosed with diabetes from a young age said:

"When I got married, because of my lifestyle, including overeating and insulin injections and due to my deteriorating health, my wife could not live with me and left me. Now I'm over 50 years old and single. I live with my brother. My bad situation is due to this deadly disease. It has destroyed my life ... I often put aside all of my medications, but I inevitably go to them, due to my bad health condition" (Participant8).

There is no doubt that severe diabetes can deprive patients from some social and financial opportunities, therefore causing them too much stress.

"My students are so annoying that I sometimes lose my temper ... when I'm teaching, my glucose falls sharply and I can't have the the opportunity in the classroom to take medications or inject insulin. That is why I'm going to leave teaching" (Participant 9).

"Sometimes life problems influence all aspects of your life. When I'm upset, I forget myself, it doesn't matter if my heartbeat goes up or I become obese or thin." (Participant 11).

\section{Interactive/economic challenges}

The medication habits of a patients with diabetes must be observed in the context of his/her social life. Like any other person in the community, diabetic patients are involved in their family lives and interact with their partner and children. In many cases, this interaction may be disturbed by diabetes, behavioral changes, diabetes treatment, and diabetes diet. A patient with diabetes needs, among other things, a special diet, emotional relationships that are free of tension, financial support to afford medications, and behavioral support to take medications. The family of the patient may not comply with these requirements, as they are more likely to face restrictions.

Diabetic patients may be faced with interactive challenges before anything else. For example, the doctor advises
"You have to walk to control your diabetes." However, the patient argues that "Well, I don't have time to walk, because I have to prepare breakfast for my husband and child every morning" (Participant 3). In such a condition, daily social interactions are barriers to the non-medical care of a patient with diabetes. In terms of nutrition, the patient may realize that "I'm not alone in the family. My kids and my husband may not be able to eat my food. I can't make food only for myself, and the rest of the family should also eat; I shouldn't eat anything unless the whole family can eat it" (Participant 5). As a consequence of these interactive and behavioral pressures, patients with diabetes often fail to follow medical instructions, and try to compensate for their non-adherence to treatment through changing their medication, its dosage, or its time of use.

Perhaps the most important interaction in the family that a patient with diabetes has is with their partner. The interaction between a diabetic patient and their partner is definitely an important part of adherence to treatment. Looking at a patient with diabetes as a disturbing agent or burden on the family instead of considering them as someone who needs physical and psychological support has negative influences on the quality of life, daily performance, and most importantly psychological health of the patient. A diabetic patient who perceived her family in an undesirable condition and was worried about her husband and children, said

"I don't want to pursue my treatment; I don't want to take my medications regularly. My husband is unhappy with my condition, and always teases me. I get upset. My life is broken. He says because I'm ill they will also get ill, as he thinks that diabetes is contiguous" (Participant 10).

In addition to emotional needs, a patient with diabetes may get dependent on others, such as their partner or children. An old person with diabetes may no longer have the ability or skill to inject insulin or even recognize medications. Dependence on others for injection of insulin may particularly affect medication use in the patients. For example, when a patient is not able to inject insulin independently after having diabetes for eleven years, it may indicate that they do not have the required skills: "I don't know how to inject my insulin, I wait for my daughter to inject it." (Participant 1).

Patient with diabetes also face the challenge of paying for treatment costs. For instance, a patient who cannot pay for high quality medications due to financial strain, becomes dependent on others to pay for medications. According to a participant: "It's in the hands of others" to provide my 
medications. Poverty, financial strain, or having inadequate insurance coverage make it more difficult for diabetic patients to adhere to treatment. For example, buying a glucometer and other medications or having routine medical tests require at least an average financial status. Drug preparation is "hard" for those with diabetes, especially for low-income patients:

"Sometimes it's hard for me to get a drug. My son who is a laborer and is currently the breadwinner in the family, is under financial pressure. My medications are too many and expensive. Honestly, sometimes I can't afford them. That's why I sometimes don't take my medications." (Participant 7).

In such a condition, it becomes harder for the patient to bear financial and economic burdens. Patients with diabetes may also become dependent on others for the provision of treatment, while they may also experience financial problems.

\section{Discussion}

The purpose of this study was to investigate the barriers of adherence to treatment among patients with type- 2 diabetes.

The study results showed that lack of trust in the medical team, patients' false beliefs, and patients' unique experiences and daily challenges prevented complete adherence to treatment.

Despite the recommendations provided by the medical team, the participants did not have sufficient trust in them, and in most cases, they did what they themselves considered appropriate. Meanwhile, the opinions and beliefs of others and their experiences with medication use were the main factors influencing the therapeutic regimen among participants. The participants said that they took medication according to their physical requirements. In such a situation, based on folk and personal beliefs, the patient challenges the medical nature of the illness and the prescriptions made by a doctor. This patient thinks that doctors "only talk" and "don't understand their condition".

Horvat et al found that age, type of treatment, and copayment were the most important predictors of treatment non-adherence. ${ }^{23}$ The Sweileh's study described this condition as lack of awareness and knowledge about diabetes as a factor contributing to adherence to treatment. ${ }^{24}$ Also, Vermeire et al found that patients with diabetes felt that they had not received enough information on diabetes, and that part of the information provided to them was unclear or not easy to remember, or that they were not provided with information at an appropriate time. ${ }^{25}$ In this study, the problem of lack of awareness appears not to be the same as the concept explained by previous studies. In other words, although adequate information on the serious consequences of diabetes was provided for the participants, in most cases, other people's beliefs about the nature of the disease, how to use medication, and medication side-effects, determined the level of treatment adherence in the diabetic patients.

In some cases, patients with diabetes act as they want and based on what they find useful. In line with the findings of other studies, this was particularly observed among patients taking insulin. In the Hertz's study (2005), the onset of insulin therapy was associated with a lack of adherence to the therapeutic regimen. ${ }^{26}$ In a study by Adisa et al (2013), insulin-dependent patients were less likely to follow the diets recommended by their doctors compared to those receiving oral tablets. ${ }^{27}$ Diabetes nurses and medical teams should pay more attention to patients' beliefs, and try to correct their false beliefs and increase their treatment adherence by respecting their cultural values. In addition, holding sessions aimed at establishing a close relationship between patients and the medical team and talking about patients' beliefs can be helpful in overcoming this serious barrier to treatment adherence.

One of the other reasons for non-adherence to treatment was having other chronic conditions in addition to diabetes. In addition, the problem of accepting the "disease", which may lead to resistance against treatment and difficult physical and psychological experiences with the disease, in many cases prevent diabetic patients from taking their medications properly. The side effects of certain diabetes medications result in disgust toward medications, increase the likelihood of medication discontinuation, and change the pattern of medication intake. These findings are in line with those of the study by Sweileh, in which the experience of medication side effects and the simultaneous use of several medications led to non-adherence to treatment. $^{28,29}$ The present study demonstrated the challenges faced by patients with diabetes in experiencing a range of other chronic conditions. Being stuck in a vicious cycle of coping with different conditions, while the treatment of each condition affects the course of other conditions, can disturb the treatment of diabetes. The common age-related conditions, such as knee arthritis, hypertension, hyperlipidemia, and spinal cord problems often worsen the complications of diabetes medications and cause the patient to change the prescribed medications. Diabetes 
can have different physical and pharmacological complications in different people. Any person can experience diabetes in a specific way, and this unique experience influences people's treatment adherence. Therefore, the medical team should analyze the unique experience of each patient, and provide customized health care recommendations in addition to general ones. Everyday life challenges are among serious barriers to treatment adherence in diabetic patients. The stress resulting from these challenges can reduce treatment adherence in the patients. Every patient has some roles and commitments that can also affect their ability to adhere to treatment.

Type-2 diabetes not only leads to physical and hormonal problems in the patients, but may also become a social issue, because the patient has interactions with other people and is engaged in daily life activities. Therefore, the conditions and challenges of everyday life, influence diabetic patients' interactions with their illness and the treatment process. The findings of our study are in line with those of other studies on mental problems and psychological health. ${ }^{30,31}$ In addition, stressful life events and depression $^{11,32}$ and their implications affect adherence to treatment in patients with type-2 diabetes. Other studies have suggested that the more stressful events experienced by the patient, the higher the chance of non-adherence to treatment, and that depression and stress can lead to reduced adherence to treatment. ${ }^{32,33}$ When caring for these patients, their roles in everyday life should be adequately examined, and any interference in the treatment adherence should be resolved through careful planning to find a balance between these two. Family participation and the support they can provide for the patients, especially when they experience psychological problems is also of high importance.

In the present study, the category of everyday life problems was separated from interactional and financial challenges, but they are not separate from one another in the real life. Part of the challenges faced by patients with type- 2 diabetes in everyday life, especially by women, is related to other family members, including husbands. Failure to play her role inside the family, and lack of behavioral and emotional support from a wife with diabetes can certainly increase her concerns in the life, therefore she may prefer to maintain the current situation. A woman with diabetes has to change the diet recommended for her condition based on what her husband or children desire, and make food according to what the family requests. In a study by Morovati Sharifabad (2007), blame from family members can make diabetic patients hopeless and reduce their ability to engage in self-care behaviors. ${ }^{34}$ In a study by Mayberry and Osborn (2012), a group of family members of diabetic patients did not support their patients despite having knowledge of diabetes (a tedious strategy), and another group unintentionally intervened in their diet (the strategy of helplessness). ${ }^{35}$ Because diabetes affects the families in addition to the patients, families of the patients should also be supported, and empathy among family members should be reinforced. However, the most important problem can be financial challenges in obtaining diabetes medications. In a qualitative study in Bangladesh by Islam et al, finical limitation was an important cause of non-adherence to treatment. This pressure is definitely higher for the families who suffer from severe economic poverty. In addition, financial dependency makes the situation more difficult for the patient, especially when the diabetic patient is a woman who is dependent on her husband or children. Low financial status may force diabetic patients to stop taking medications, reduce their use, or take medications with a lower quality. According to the findings, financial strain in the family can prevent the provision of required medications for controlling diabetes. This is undoubtedly more challenging for those patients who have other underlying conditions. These findings were consistent with those of Edessa et al about the role of financial weakness in adherence to diet therapy. ${ }^{36}$ Balkrishnan et al (2003) found that $10 \%$ increase in adherence to diet therapy was associated with a one-fourth reduction in treatment costs. ${ }^{37}$ Diabetes and its treatment can affect patients and their families financially. These financial challenges may prevent adherence to treatment. Providing support for those patients with financial problems and introducing them to charitable organization can solve their problems to some extent. In terms of non-adherence to treatment, Bezie (2006) suggested that physicians should talk to the patients on how to follow treatment recommendations rather than prescribing a second drug or changing the current medications. ${ }^{38}$ If doctors spend more time with diabetic patients, they will have the opportunity to discuss their health problems more conveniently. However, it should also be pointed out that physicians and nurses should pay more attention to the patients' knowledge of their own bodies. Diabetic patients understand their 
bodily internal forces better than any other person, and they themselves can find a balance between taking medications and managing their everyday life. "Balancing the body" is what patients themselves understand better. Finding a balance on the basis of the requirements of every life, financial concerns, and physical needs, may not be easily accepted by a physician or a nurse, but is understandable by the patients themselves according to their perspectives.

According to the findings of this study, these barriers are inseparable from one another and sometimes are strongly intertwined. A patient's lack of knowledge on diabetes management can be improved through receiving support from competent and knowledgeable family members. A calm atmosphere in the family and the presence of social capital within the family (including trust and support) can reduce stress and ultimately improve adherence to treatment in diabetic patients. Family support, interactively and economically, can certainly contribute to reducing the pressure on the patients, especially in older adults with diabetes. It can also reduce the burden of comorbid conditions on the patient. The strength of this study was that it was the first study to examine barriers to adherence to treatment among Iranian patients with diabetes. Given the effects of culture on treatment adherence, the study results can help in deigning appropriate intervention programs to increase it among patients with diabetes. This study was conducted on a small group of patients with diabetes in an urban area of Iran, and the results can only be generalized to this group. One of the limitations of this research was that the interviews were conducted and implemented in Kurdish but the final report was provided in Persian. In the present study, non-adherence to treatment was examined in general, therefore, future studies are suggested to examine and compare care dimensions in patients who take anti-diabetic medications and those who take insulin. In addition, it is suggested that the category of "lived experiences" should be explained based on the health behavior models.

One of the new findings of this study was diabetic patients' lack of trust in doctors' recommendations and accepting folk beliefs, an issue that warrants more attention from healthcare providers. Patients with type-2 diabetes should be provided with simple and comprehensible instructions about their condition, and their doubts about scientific and folk beliefs should be addressed properly.

\section{Conclusion}

Lack of trust in the medical team and each patient's unique experiences and challenges in everyday life, are barriers to adherence to treatment in patients with diabetes type 2 . Therefore, in addition to trying to gain the patient's trust, the medical team should focus on designing a particular care program for each patient based on their lived experiences and unique roles and challenges in life to increase their adherence to treatment.

\section{Acknowledgments}

The authors wish to sincerely thank all patients with diabetes who participated in the research, the chairman of the health and treatment center of Saghez, and the personnel of the diabetes center in this city. The study was conducted without any external funding.

\section{Disclosure}

The authors declare no conflicts of interest in this work.

\section{References}

1. Ghane'i R, Golkar F. Foot care in depressed and non-depressed diabetic patients. Mod Care J. 2013;10(2):124-131.

2. Ghanei Geshlagh R, Hemmati M, Baghi V. A study on the relation between body mass index and sleep apnea in patients suffering diabetes type 2. J Diabetes Nurs. 2014; 1(2):12-20.

3. Haji-Arabi E, Nobahar M, Ghorbani R. Relationship between depression and knowledge about diabetes with the amount of self-care in patients with type 2 diabetes. Koomesh. 2018;20(2):210-220.

4. Maslakpak M, Ahmadi F, Anoosheh M. Spiritual beliefs and quality of life: A qualitative research about diabetic adolescent girls' perception. Koomesh. 2011;12(2):144-151.

5. Mohamadzadeh S, Ezate G. A determination of self-care performance among diabetic patients in endocrine clinic of Taleghane hospital in Tehran. Iran J Nurs Res. 2014;4(31):11-18.

6. Masoudnia E, Foroozannia K, Montazeri M. Relationship between perceived social support and adherence to medical advices among patients with coronary heart disease after by-pass surgery. $J$ Shahid Sadoughi Univ Med Sci Health Serv. 2012;19(6):798-806.

7. Lerman I. Adherence to treatment: the key for avoiding long-term complications of diabetes. Arch Med Res. 2005;36(3):300-306 doi:10.1016/j.arcmed.2004.12.001

8. Gonzalez JS, McCarl LA. Cognitive behavioral therapy for adherence and depression (CBT-AD) in type 2 diabetes. J Cogn Psychother. 2010;24(4):329. doi:10.1891/0889-8391.24.4.329

9. Blackburn DF, Swidrovich J, Lemstra M. Non-adherence in type 2 diabetes: practical considerations for interpreting the literature. Patient Prefer Adherence. 2013;7:183. doi:10.2147/PPA.S30613

10. Ratanawongsa N, Karter AJ, Parker MM, et al. Communication and medication refill adherence: the Diabetes Study of Northern California. JAMA Intern Med. 2013;173(3):210-218. doi:10.1001/ jamainternmed.2013.1216

11. Osborn CY, Egede LE. The relationship between depressive symptoms and medication nonadherence in type 2 diabetes: the role of social support. Gen Hosp Psychiatry. 2012;34(3):249-253. doi:10.1016/j.genhosppsych.2012.01.015 
12. Delamater AM. Improving patient adherence. Clin Diabetes. 2006;24 (2):71-77. doi:10.2337/diaclin.24.2.71

13. Mashrouteh M, Khanjani N. Evaluation of oral medication adherence and its related factors in type II diabetic patients in Iran: a systematic review. Int J Diabetes Res. 2017;6(1):24-33.

14. Ho PM, Rumsfeld JS, Masoudi FA, et al. Effect of medication nonadherence on hospitalization and mortality among patients with diabetes mellitus. Arch Intern Med. 2006;166(17):1836-1841. doi:10.1001/archinte.166.17.1836

15. Boye KS, Curtis SE, Lage MJ, Garcia-Perez L-E. Associations between adherence and outcomes among older, type 2 diabetes patients: evidence from a Medicare supplemental database. Patient Prefer Adherence. 2016;10:1573-1581. doi:10.2147/PPA.S107543

16. Jaam M, Hadi MA, Kheir N, et al. A qualitative exploration of barriers to medication adherence among patients with uncontrolled diabetes in Qatar: integrating perspectives of patients and health care providers. Patient Prefer Adherence. 2018;12:2205. doi:10.2147/ PPA.S176067

17. Mousavizadeh S, Ashktorab T, Ahmadi F, ZandI M. Evaluation of barriers to adherence to therapy in patients with diabetes. $J$ Diabetes Nurs. 2016;4(3):94-108.

18. Creswell JW, Creswell JD. Research Design: Qualitative, Quantitative, and Mixed Methods Approaches. Thousand Oaks (CA): Sage Publications; 2002.

19. Nasiri Amiri F, Ramezani Tehrani F, Simbar M, Thamtan M, Ali R. Concerns of women with polycystic ovary syndrome: a qualitative study. Iran J Endocrinol Metab. 2013;15(1):41-51.

20. Polit DF, Hungler B. Nursing Research. 5th ed. Philadelphia (PA): Lippincott; 2001:30-50.

21. Asgari M, Mohammadi E, Fallahi KM, Tamadon M. The perception of chronic renal failure patients from advocacy resources in adjustment with hemodialysis: a qualitative study. Iran J Crit Care Nurs 2011;3(4):133-140.

22. Graneheim UH, Lundman B. Qualitative content analysis in nursing research: concepts, procedures and measures to achieve trustworthiness. Nurse Educ Today. 2004;24(2):105-112. doi:10.1016/j. nedt.2003.10.001

23. Horvat O, Popržen J, Tomas A, Kusturica MP, Tomić Z, Sabo A. Factors associated with non-adherence among type 2 diabetic patients in primary care setting in eastern Bosnia and Herzegovina. Primary Care Diabetes. 2018;12(2):147-154.

24. Sweileh WM, Sa'ed HZ, Nab'a RJA, et al. Influence of patients' disease knowledge and beliefs about medicines on medication adherence: findings from a cross-sectional survey among patients with type 2 diabetes mellitus in Palestine. BMC Public Health. 2014;14(1):94. doi:10.1186/1471-2458-14-94

25. Vermeire E, Hearnshaw H, Rätsep A, et al. Obstacles to adherence in living with type-2 diabetes: an international qualitative study using meta-ethnography (EUROBSTACLE). Prim Care Diabetes. 2007;1 (1):25-33. doi:10.1016/j.pcd.2006.07.002
26. Hertz RP, Unger AN, Lustik MB. Adherence with pharmacotherapy for type 2 diabetes: a retrospective cohort study of adults with employer-sponsored health insurance. Clin Ther. 2005;27(7):10641073. doi:10.1016/j.clinthera.2005.07.009

27. Adisa R, Fakeye TO. Effect of number and type of antidiabetes medications on adherence and glycemia of ambulatory type 2 diabetes patients in southwestern Nigeria. Pharm Pract. 2013;11(3):156. doi:10.4321/S1886-36552013000300006

28. Arifulla M, Lisha Jenny J, Sreedharan J, Muttappallymyalil J, Basha SA. Patients' adherence to anti-diabetic medications in a hospital at Ajman, UAE. Malaysian J Med Sci. 2014;21(1):44.

29. Wabe NT, Angamo MT, Hussein S. Medication adherence in diabetes mellitus and self management practices among type-2 diabetics in Ethiopia. N Am J Med Sci. 2011;3(9):418. doi:10.4297/najms.2011.3418

30. Poursharifi H, Babapour J Memory, health locus of control and adherence in type II diabetic patients in Iran-Tabriz. Procedia-Social Behav Sci. 2011;30:2621-2624. doi:10.1016/j.sbspro.2011.10.513

31. Kreyenbuhl J, Leith J, Medoff DR, et al. A comparison of adherence to hypoglycemic medications between type 2 diabetes patients with and without serious mental illness. Psychiatry Res. 2011;188(1):109114. doi:10.1016/j.psychres.2011.03.013

32. Walders-Abramson N, Venditti EM, Ievers-Landis CE, et al. Relationships among stressful life events and physiological markers, treatment adherence, and psychosocial functioning among youth with type 2 diabetes. $J$ Pediatr. 2014;165(3):504-508. doi:10.1016/j. jpeds.2014.05.020

33. Zhang J, Xu C-p, Wu H-x, et al. Comparative study of the influence of diabetes distress and depression on treatment adherence in Chinese patients with type 2 diabetes: a cross-sectional survey in the People's Republic of China. Neuropsychiatr Dis Treat. 2013;9:1289.

34. Morovati SMA, Rouhani TN. Social support and self-care behaviors in diabetic patients referring to Yazd Diabetes Research Center. Zahedan J Res Med Sci. 2008;9(4):275-284.

35. Mayberry LS, Osborn CY. Family support, medication adherence, and glycemic control among adults with type 2 diabetes. Diabetes Care. 2012;35(6):1239-1245. doi:10.2337/dc11-2103

36. Adisa R, Fakeye TO, Fasanmade A. Medication adherence among ambulatory patients with type 2 diabetes in a tertiary healthcare setting in southwestern Nigeria. Pharm Pract. 2011;9(2):72-81.

37. Balkrishnan R, Rajagopalan R, Camacho FT, Huston SA, Murray FT, Anderson RT. Predictors of medication adherence and associated health care costs in an older population with type 2 diabetes mellitus: a longitudinal cohort study. Clin Ther. 2003;25(11):2958-2971.

38. Bezie Y, Molina M, Hernandez N, Batista R, Niang S, Huet D. Therapeutic compliance: a prospective analysis of various factors involved in the adherence rate in type 2 diabetes. Diabetes Metab. 2006;32(6):611-616. doi:10.1016/S1262-3636(07)70316-6 


\section{Supplementary material}

\section{The interview guideline}

Please explain how you found out that you had diabetes.

Please explain a little about the cares you receive?

What resources have you used to control or treat your illness?
How well have you adhered to the recommendations provided by your doctor?

What challenges have you faced when trying to adhere to treatment? Please explain.

\section{Publish your work in this journal}

Diabetes, Metabolic Syndrome and Obesity: Targets and Therapy is an international, peer-reviewed open-access journal committed to the rapid publication of the latest laboratory and clinical findings in the fields of diabetes, metabolic syndrome and obesity research. Original research, review, case reports, hypothesis formation, expert opinion and commentaries are all considered for publication. The manuscript management system is completely online and includes a very quick and fair peer-review system, which is all easy to use. Visit http://www.dovepress.com/testimonials.php to read real quotes from published authors. 